Arq. Bras. Med. Vet. Zootec., v.67, n.1, p.131-139, 2015

\title{
Crescimento e metabolismo do nitrogênio em juvenis de Trachinotus marginatus alimentados com diferentes níveis proteicos
}

\author{
[Growth and nitrogenous metabolism of juveniles Trachinotus marginatus feeding \\ with differently protein levels]
}

E.M. Silva, J.M. Monserrat, L.A. Sampaio, M.B. Tesser

Universidade Federal do Rio Grande - FURG - Rio Grande, RS

\begin{abstract}
RESUMO
O objetivo deste trabalho foi avaliar o crescimento e alterações no metabolismo do nitrogênio, além da composição do fígado e do músculo de juvenis de pampo Trachinotus marginatus alimentados com 43, 54 ou $64 \%$ de proteína bruta (PB43, PB54 e PB64, respectivamente). Grupos de 10 juvenis $(1,47 \pm 0,14 \mathrm{~g})$ foram estocados em nove tanques de 50L, em sistema de recirculação de água marinha, durante 55 dias, alimentados quatro vezes ao dia com as rações pré-definidas. O ganho em peso, a taxa de crescimento específico e a conversão alimentar não apresentaram diferença significativa $(\mathrm{P}>0,05)$. Contudo, o acréscimo de proteína consumida aumentou o índice hepatossomático e a taxa de excreção de amônia pós-prandial, bem como diminuiu a retenção proteica. Os peixes alimentados com a dieta PB43 apresentaram menor concentração da transaminase glutâmico oxalacética hepática, além de menor concentração de triglicerídeos no músculo e fígado $(\mathrm{P}<0,05)$. A composição da carcaça, o teor de glicogênio e de proteínas totais para músculo e fígado não mostraram diferenças significativas $(\mathrm{P}>0,05)$, excetuando o maior teor de lipídios da carcaça no tratamento PB43. Concluímos que a melhor utilização da proteína por juvenis de pampo é observada quando eles são alimentados com uma dieta contendo $43 \%$ de proteína.
\end{abstract}

Palavras-chave: amônia, proteína, transaminases, Trachinotus marginatus

\begin{abstract}
The experiment aimed to evaluate the growth, the nitrogen metabolism and liver and muscle composition of juvenile pompano Trachinotus marginatus fed with different protein levels (PB43, PB54, PB64). Groups of 10 juveniles $(1.47 \pm 0.14 \mathrm{~g})$ were stocked in nine tanks with $50 \mathrm{~L}$ in a marine recirculating aquaculture system during 55 days. Fish were fed four times a day. The weight gain, specific growth rate and feed conversion rate did not present significant differences $(P>0.05)$. However, the increase in protein consumption augmented the hepatosomatic index, the pos prandial ammonia excretion rate and reduced the protein efficiency rate. Fish fed with PB43 presented lower hepatic glutamic oxaloacetic transaminase and lower concentration of triglycerides in muscle and liver $(P<0.05)$. Carcass composition, glycogen and muscle and liver protein content did not present significant differences $(P>0.05)$, with the exception of the lipid content in fish carcass fed with PB43. It is concluded that the better protein utilization in juvenile pompano is observed when they are fed with $43 \%$ protein.
\end{abstract}

Keywords: ammonia, protein, transaminases, Trachinotus marginatus

\section{INTRODUÇÃO}

A proteína é um dos nutrientes mais importantes, pois é necessária para o crescimento, a manutenção e a reprodução dos peixes, podendo ser utilizada como relevante fonte energética (Martínez-Palácios et al., 2007). A inclusão de níveis adequados de proteína na dieta assegura alta eficiência proteica (Carvalho et al., 2010), o

Recebido em 26 de julho de 2013

Aceito em 9 de setembro de 2014

E-mail: edu.aquicultura@gmail.com que é importante, pois esse é o constituinte mais caro nas formulações de dietas para organismos aquáticos (Souza et al., 2011). Dessa forma, a inclusão de níveis adequados de proteína promove melhor crescimento dos peixes com menor custo.

Por outro lado, quando a proteína é ofertada em excesso, seus aminoácidos podem ser transaminados e/ou desaminados e, nesse caso, o esqueleto carbônico resultante é desviado para 
rotas metabólicas energéticas (Melo et al., 2006), resultando em um aumento da excreção de nitrogênio, principalmente na forma de amônia não ionizada (Sá et al., 2008). O processo denominado de transaminação que ocorre principalmente no fígado, embora também seja observado no tecido muscular (Carter e Houlihan, 2001), tem como principais enzimas a transaminase glutâmico pirúvica (TGP) e a transaminase glutâmico oxalacética (TGO) (Nelson e Cox, 2002), e provoca um grande acúmulo de glutamato no fígado, que é usado na gliconeogênese ou entra no ciclo de Krebs (Das, 2002).

Para juvenis de Sparus aurata alimentados com rações em que a proteína foi substituída por carboidratos, houve diminuição da concentração da TGP conforme o teor de proteína da dieta foi reduzido, indicando uma relação direta dessa concentração enzimática com o conteúdo de proteína oferecido aos peixes. Entretanto, a concentração da enzima TGO não mostrou nenhuma alteração frente à modificação do teor proteico da dieta ofertada (Fernández et al., 2007). Em contraste, Cho e Heo (2011) demonstraram que a atividade da TGP não foi alterada em Paralichthys olivaceus alimentados com 50, 55 ou $60 \%$ de proteína bruta. Esses dados mostram que a relação entre a atividade das enzimas chave do catabolismo de aminoácidos com a concentração de proteína na ração consumida não é bem estabelecida, tampouco a resposta enzimática segue um padrão (Peres e Olivia-Teles, 2007), embora essa relação seja utilizada como ferramenta para avaliar o metabolismo proteico do animal (Melo et al., 2006).

Espécies do gênero Trachinotus (Carangidae) são consideradas apropriadas para aquicultura por apresentar rápida adaptação ao cativeiro, boa tolerância às condições ambientais extremas e crescimento rápido (Jory et al., 1985; Craig, 2000). O pampo, Trachinotus marginatus (Cuvier 1832), tem distribuição do Rio de Janeiro, no Brasil, até o Norte da Argentina (Fischer et al., 2004). Os juvenis são comuns na zona de arrebentação do litoral do Rio Grande do Sul (Lima e Vieira, 2009). A espécie é considerada eurialina (Sampaio et al., 2003), com maior tolerância à amônia e nitrito em salinidade 10\%o (Costa et al., 2008). Porém, mais informações a respeito do manejo de criação do pampo são necessárias, principalmente no que se refere ao manejo alimentar da espécie. Portanto, o presente estudo teve como objetivo avaliar o efeito de diferentes níveis proteicos sobre o crescimento, composição corporal e a taxa de excreção de amônia, além de determinar as concentrações de triglicerídeos, colesterol e glicogênio, e as concentraçãos enzimáticas da TGP e da TGO em fígado e músculo de juvenis de pampo T. marginatus.

\section{MATERIAL E MÉTODOS}

Os juvenis de pampo foram coletados durante o verão na zona de arrebentação na praia do Cassino (32 04'54.00”S; 52॰09'48.00” W), Rio Grande, Rio Grande do Sul,- Brasil, por meio de rede de arrasto e transportados imediatamente à Estação Marinha de Aquicultura da Universidade Federal do Rio Grande - FURG (Autorização para concentraçãos com finalidade científica $\mathrm{n}^{\circ}$ 31890-2, Ministério do Meio Ambiente, Instituto Chico Mendes de Conservação da Biodiversidade, Sistema de Autorização e Informação em Biodiversidade - SISBIO).

Os peixes passaram por 10 dias de aclimatação às condições experimentais. Nesse período, os peixes foram alimentados com ração comercial quatro vezes ao dia até a saciedade aparente. Receberam banhos profiláticos em formol (50ppm) durante uma hora por três dias seguidos. Posteriormente, os peixes, com peso médio de $1,47 \pm 0,14 \mathrm{~g}$, foram estocados aleatoriamente em 9 tanques de 50L (3 tanques para cada dieta), na densidade de 10 peixes por tanque. Os tanques estavam conectados a um sistema de recirculação de água dotado de biofiltro, esterilizador ultravioleta e "skimmer".

Três dietas isoenergéticas semipurificadas foram formuladas e analisadas de acordo com o método proposto pela AOAC (1995) (Tab. 1). Os ingredientes secos foram homogeneizados previamente à mistura da água e do óleo de peixe. A água foi aquecida a $40^{\circ} \mathrm{C}$ e adicionada na proporção de $30 \%(\mathrm{p} / \mathrm{v})$ à mistura seca para dissolver a gelatina e melhorar a consistência da massa a ser peletizada. Posteriormente à peletização, as dietas foram secas em estufa com circulação forçada de ar a $60^{\circ} \mathrm{C}$ e armazenada a $20^{\circ} \mathrm{C}$. 
Tabela 1. Ingredientes e composição proximal de dietas testadas na alimentação de juvenis do pampo prateado (Trachinotus marginatus) contendo 43, 54 e $64 \%$ de proteína bruta. Valores em termos de matéria seca

\begin{tabular}{|c|c|c|c|}
\hline \multirow[t]{2}{*}{ Ingredientes $\left(\mathrm{g} \mathrm{Kg}^{-1}\right)$} & \multicolumn{3}{|c|}{ Dieta } \\
\hline & PB43 & PB54 & PB64 \\
\hline Farinha peixe & 50 & 50 & 50 \\
\hline Caseína & 350 & 440 & 530 \\
\hline Gelatina & 80 & 110 & 140 \\
\hline Dextrina & 300 & 180 & 60 \\
\hline Óleo de Peixe & 100 & 100 & 100 \\
\hline Celulose & 89 & 89 & 89 \\
\hline Mist. Mineral e vit. & 10 & 10 & 10 \\
\hline vit. $\mathrm{C}$ & 1 & 1 & 1 \\
\hline Carboximetilcelulose & 20 & 20 & 20 \\
\hline Total & 1000 & 1000 & 1000 \\
\hline \multicolumn{4}{|c|}{ Análise proximal ( $\mathrm{g} \mathrm{Kg}^{-1}$ matéria seca) } \\
\hline Proteína bruta analisada & 430,9 & 541,3 & 642,2 \\
\hline Extrato etéreo & 87 & 100,5 & 104,6 \\
\hline Extrativo não nitrogenado & 389,6 & 263,9 & 160,5 \\
\hline Fibra bruta & 71,4 & 70,1 & 65,1 \\
\hline Cinzas & 21,8 & 24,2 & 27,5 \\
\hline Umidade & 80,6 & 57 & 57,5 \\
\hline Energia bruta $\left(\mathrm{KJ} \mathrm{g}^{-1}\right)$ & 18,74 & 19,17 & 19,59 \\
\hline $\mathrm{PB} / \mathrm{EB}\left(\mathrm{g} \mathrm{KJ}^{-1}\right)$ & 23 & 28,23 & 32,78 \\
\hline
\end{tabular}

Os animais foram alimentados quatro vezes por dia (09:00, 12:00, 15:00 e 18:00h) até a saciedade aparente por 55 dias com suas respectivas dietas. Os parâmetros de qualidade de água foram mensurados em todos os tanques, sendo apresentados como um único valor de média \pm desvio padrão, uma vez que não se diferem estatisticamente entre os tratamentos. A temperatura e o oxigênio dissolvido foram medidos diariamente por meio de oxímetro digital (YSI 550, Yellow Springs, OH, USA). A salinidade foi mensurada por meio de refratômetro (Atago, modelo 103, Tóquio, Japão). A alcalinidade e a concentração de amônia foram mensuradas duas vezes por semana, de acordo com a metodologia de APHA (American..., 2005) e Solorzano (1969), respectivamente.

A taxa de excreção de amônia foi determinada ao final do experimento de crescimento. Para tanto, todos os peixes de cada unidade experimental foram submetidos a jejum de 48 horas para esvaziar o trato digestório. Passado o período de jejum, foi ofertado $1,5 \mathrm{~g}$ da respectiva ração a cada tanque. Após o processo de alimentação, os peixes de cada unidade experimental foram transferidos para novos tanques de $30 \mathrm{~L}$, onde permaneceram durante todo o período de coleta de água. A água dos tanques estava à mesma temperatura e salinidade do sistema experimental original. A partir desse momento, foi realizada uma coleta de água inicial e, a cada hora, até $6 \mathrm{~h}$ após a alimentação. A amônia total foi determinada de acordo com Solorzano (1969). A taxa de excreção de amônia foi calculada pela diferença entre a concentração de amônia total na água antes da alimentação e após a alimentação, a cada hora, por 6 horas. A cada hora foram tomadas amostras de água de cada um dos tanques, tendo assim três réplicas de cada tratamento por hora. Esse cálculo foi feito a partir da seguinte fórmula:

Taxa de excreção de amônia total pós-prandial $=[$ concentração final de AT concentração inicial de AT)] x volume de água (L) / (biomassa do tanque (g) $\mathrm{X}$ tempo transcorrido $(\mathrm{H}))$

Em que AT: concentração de amônia total $\left(\mathrm{NH}_{3}+\mathrm{NH}_{4}-\mathrm{N} \mathrm{mg} / \mathrm{L}\right)$.

Ao término da determinação da taxa de excreção pós-prandial, foi realizada a biometria final $\mathrm{e}$ coleta dos tecidos. Todos os peixes foram anestesiados em benzocaína (50 ppm) e mortos 
por secção medular. O peso e o comprimento foram tomados por meio de balança analítica (Marte, BL-3200H, São Paulo, Brasil) com precisão de $0,01 \mathrm{~g}$ e ictiômetro, respectivamente.

O desempenho zootécnico dos juvenis foi avaliado usando-se os seguintes índices:

Ganho em peso (GP)

$=$ peso final - peso inicial

Taxa crescimento específico (TCE)

$=\left[(\ln\right.$ peso final $-\ln$ peso inicial $) / \mathrm{n}^{\mathrm{o}}$ dias transcorridos)] x 100

Conversão alimentar (CA)

$=$ peso seco de alimento consumido (g) / (biomassa final - biomassa inicial $(\mathrm{g})$ )

Retenção proteica (RP)

$=[$ biomassa final $\mathrm{X}$ teor de proteína final da carcaça) - (biomassa inicial X teor de proteína inicial da carcaça) / consumo de proteína (g)] X 100

Consumo de Proteína

= Total de alimento consumido $(\mathrm{g}) \mathrm{X}$ conteúdo de proteína da dieta $(\mathrm{g})$

Retenção lipídica (RL)

$=[$ (biomassa final $\mathrm{X}$ teor de lipídios final da carcaça)-(biomassa inicial $X$ teor de lipídios inicial da carcaça) / consumo de lipídios (g)] X 100

Consumo de Alimento (CA)

$=100 \mathrm{X}$ [média de consumo diário $(\mathrm{g}) /$ (biomassa final $(\mathrm{g})+$ biomassa inicial $(\mathrm{g})) / 2]$

Índice hepatossomático (IHS)

$=100 \mathrm{X}$ (peso do fígado $(\mathrm{g}) /$ peso corporal $(\mathrm{g})$ )

Índice Viscerossomático (IVS)

$=100 \mathrm{X}($ peso das vísceras $(\mathrm{g}) /$ peso corporal $(\mathrm{g})$ )

Após a eutanásia de todos os peixes, as amostras de fígado e de músculo foram imediatamente retiradas e congeladas em nitrogênio líquido e, posteriormente, armazenadas em ultrafreezer ($80^{\circ} \mathrm{C}$ ) até a realização das determinações bioquímicas. Todos os fígados e vísceras foram pesados para cálculo do IHS e IVS. A umidade, a proteína bruta, o extrato etéreo e o teor de cinzas das carcaças foram determinados por métodos padrões da AOAC (Association..., 1995).

O extrato produzido para determinação do teor de triglicerídeos totais (TG), colesterol total (COL) e glicogênio (GG) foi obtido por meio de digestão ácida em banho de ultrassom (LaizCarrión et al., 2012). Os extratos foram, então, centrifugados a $13.000 \mathrm{x}$ g por 30 minutos a $4^{\circ} \mathrm{C}$ e o sobrenadante, congelado em ultrafreezer ($\left.80^{\circ} \mathrm{C}\right)$. O conteúdo $\left(\mathrm{mg} \mathrm{g}^{-1}\right.$ de tecido úmido) de TG, COL e GG do fígado e do músculo foi determinado em três amostras de cada tanque, totalizando nove repetições para cada tratamento. As leituras foram feitas por meio de espectrofotômetro (Biotek, LX808, Winooski, Estados Unidos) em 490nm, usando-se os kits comerciais Triglicérides Enzimático Líquido, Colesterol Enzimático Líquido e Glicose Enzimática Líquida (Doles, Goiânia - GO, Brasil), respectivamente. A concentração de GG foi calculada com base na diferença entre a concentração de glicose no extrato bruto e a concentração de glicose no extrato digerido com a enzima amiloglicosidase de Aspergillus niger, conforme protocolo de Nery e Santos (1993).

Para a determinação da concentração de proteínas totais e das transaminases (TGP e TGO), outras três amostras de cada tanque (totalizando nove repetições para cada tratamento) de fígado e de músculo foram homogeneizadas $(1: 5 \mathrm{P} / \mathrm{V})$ em tampão Tris- $\mathrm{HCl}$ (100mM, pH 7,75) com EDTA (2mM) e $\mathrm{Mg}^{2+}(5$ $\mathrm{mM}$ ) (Amado et al., 2011). O homogeneizado foi centrifugado a $10.000 \mathrm{x}$ g por 20 minutos a $4^{\circ} \mathrm{C}$. O sobrenadante dessa centrifugação foi armazenado em ultrafreezer $\left(-80^{\circ} \mathrm{C}\right)$. O conteúdo de proteínas totais do fígado e do músculo foi determinado para todos os extratos obtidos em fluorímetro (Perkin Elmer, Victor 2, Perkin Elmer, Massachusetts, Estados Unidos) em 550nm, usando kit comercial, Proteínas Totais (Doles, Goiânia - GO, Brasil), com base em Biureto. O conteúdo de proteínas totais foi expresso em mg de proteína/g de tecido úmido. A determinação da concentração de TGO e TGP no fígado e no músculo foi realizada em todos os extratos obtidos em espectrofotômetro (Biotek, LX808 Winooski, Estados Unidos) em 490nm com kit comercial, Transaminases (Doles, Goiânia - GO, Brasil).

Os dados foram analisados quanto à homogeneidade e normalidade pelos testes de Levene e Shapiro-Wilk, respectivamente. A análise de variância uma via foi aplicada à todos os dados e quando foi encontrado diferença significativa, o teste de Duncan foi utilizado. Todos os testes foram realizados utilizando-se $5 \%$ como nível de significância. 


\section{RESULTADOS E DISCUSSÃO}

Os parâmetros de qualidade da água temperatura, salinidade, oxigênio dissolvido, alcalinidade e concentração de amônia total dissolvida permaneceram em: $26,5 \pm 0,75^{\circ} \mathrm{C}$, $34 \pm 2 \%$, 6,14 $\pm 0,22 \mathrm{mg} \mathrm{L}_{-1}^{-1}, 132,7 \pm 14,63 \mathrm{mg} \mathrm{L}^{-1} \mathrm{de}$ $\mathrm{CaCO}_{3}$ e $0,18 \pm 0,16 \mathrm{mg} \mathrm{L}^{-1}$, respectivamente.

A sobrevivência de $100 \%$ para todos os tratamentos demonstra que os níveis proteicos testados não influenciaram nesse parâmetro, como também foi relatado para $T$. carolinus (Lazo et al., 1998) e Mugil liza (Carvalho et al., 2010).

Os juvenis de pampo alimentados com as diferentes dietas apresentaram o mesmo ganho em peso e taxa de crescimento específico
(Tab. 2), o que sugere que todos os tratamentos supriram as necessidades proteicas e energéticas. Isso permite inferir que a necessidade proteica para a espécie não seja superior a $43 \%$, uma vez que a taxa de crescimento específico aumenta até que seja atingida a exigência proteica da espécie (Rema et al., 2008). Esse teor de proteína bruta é semelhante ao reportado por Lazo et al. (1998), que sugeriram $45 \%$ de proteína bruta para juvenis de $T$. carolinus.

Os peixes podem regular a ingesta tanto para atingir as necessidades energéticas (Vivas et al., 2006) como também para atingir as necessidades proteicas (Vivas et al., 2006; Siddiqui e Khan, 2009). Esses fatos podem auxiliar a explicar por que os peixes do tratamento PB64 consumiram significativamente menos alimento do que os dos demais tratamentos (Tab. 2).

Tabela 2. Índices zootécnicos de juvenis de pampo Trachinotus marginatus alimentados com diferentes níveis de proteína na ração

\begin{tabular}{lccc}
\hline Variável & \multicolumn{3}{c}{ Dieta } \\
\hline & PB43 & PB54 & PB64 \\
\hline Peso inicial $(\mathrm{g})$ & $1,45 \pm 0,05$ & $1,45 \pm 0,02$ & $1,48 \pm 0,01$ \\
Peso final $(\mathrm{g})$ & $7,02 \pm 0,16$ & $6,77 \pm 0,21$ & $7,02 \pm 0,58$ \\
GP $(\mathrm{g})$ & $5,22 \pm 0,21$ & $5,32 \pm 0,22$ & $5,53 \pm 0,58$ \\
TCE $\left(\% \mathrm{dia}^{-1}\right)$ & $1,22 \pm 0,08$ & $1,23 \pm 0,06$ & $1,22 \pm 0,09$ \\
CA & $1,30 \pm 0,12$ & $1,33 \pm 0,02$ & $1,38 \pm 0,13$ \\
RP $(\%)$ & $39,79 \pm 1,02 \mathrm{a}$ & $31,39 \pm 1,65 \mathrm{~b}$ & $33,86 \pm 1,30 \mathrm{~b}$ \\
RL $(\%)$ & $230,76 \pm 12,83$ & $199,64 \pm 4,18$ & $215,33 \pm 18,29$ \\
TCA $(\%)$ & $0,078 \pm 0,003 \mathrm{~b}$ & $0,074 \pm 0,006 \mathrm{~b}$ & $0,066 \pm 0,003 \mathrm{a}$ \\
CP $(\mathrm{g})$ & $69,75 \pm 0,52 \mathrm{a}$ & $78,91 \pm 2,25 \mathrm{~b}$ & $91,19 \pm 1,28 \mathrm{c}$ \\
IHS & $3,25 \pm 0,66 \mathrm{~b}$ & $3,40 \pm 0,74 \mathrm{ab}$ & $3,74 \pm 0,72 \mathrm{a}$ \\
IVS & $8,76 \pm 1,28$ & $8,85 \pm 0,91$ & $9,09 \pm 1,39$ \\
\hline
\end{tabular}

Médias seguidas de letras diferentes, nas linhas, diferem entre si pelo teste de Duncan, a 5\% de probabilidade. GP: ganho em peso; TCE: taxa de crescimento específico; CA: conversão alimentar; RP: retenção proteica; RL: retenção lipídica; TCA: taxa de consumo alimentar; CP: consumo de proteína; IHS: índice hepatossomático e IVS: índice viscerossomático.

Embora os peixes do tratamento PB43 tenham ingerido menor quantidade de proteína (Tab. 2), o crescimento desses peixes não apresentou diferença significativa $(\mathrm{P}<0,05)$ dos demais grupos, resultando, dessa forma, em melhor retenção proteica. Esse fato contrasta com outros estudos que demonstram que peixes alimentados com níveis proteicos acima de seu ótimo apresentam menor crescimento (Siddiqui e Khan, 2009; Carvalho et al., 2010).
O teor de umidade, de proteína bruta e de cinzas não diferiram entre as carcaças dos animais alimentados com as diferentes dietas (Tab. 3). Por outro lado, o teor de extrato etéreo nos peixes do tratamento PB43 foi significativamente maior $(\mathrm{P}<0,05)$; isso possivelmente foi provocado pelo maior teor de carboidratos dessa dieta, uma vez que os carboidratos podem aumentar a atividade de enzimas lipogênicas (Kumar et al., 2009). 
Tabela 3. Composição proximal da carcaça de juvenis de pampo Trachinotus marginatus alimentados com diferentes níveis de proteína na ração

\begin{tabular}{lccc}
\hline Variável & \multicolumn{3}{c}{ Dieta } \\
\hline & PB43 & PB54 & PB64 \\
\hline Umidade & $629 \pm 6,5$ & $637 \pm 10,5$ & $637,7 \pm 4,8$ \\
Proteína & $178,7 \pm 4,8$ & $172,8 \pm 4,2$ & $185,1 \pm 6,8$ \\
Extrato etéreo & $154,5 \pm 3,4 \mathrm{a}$ & $146,2 \pm 5,1 \mathrm{~b}$ & $144,9 \pm 3,0 \mathrm{~b}$ \\
Cinzas & $44,1 \pm 2,4$ & $45,7 \pm 2,0$ & $42,7 \pm 2,4$ \\
\hline
\end{tabular}

Médias seguidas de letras diferentes, nas linhas, diferem entre si pelo teste de Duncan, a 5\% de probabilidade. Valores expressos para matéria úmida $\left(\mathrm{g} \mathrm{Kg}^{-1}\right)$.

Após 6 horas do início do teste de excreção, verificou-se que os peixes alimentados com a dieta PB43 apresentaram pico de excreção pósprandial significativamente menor $(\mathrm{P}<0,05)$ do que quando comparado à taxa de excreção dos peixes do tratamento PB64 (Fig. 1). O aumento da excreção de produtos nitrogenados está relacionado com a utilização dos aminoácidos como componentes energéticos (Sá et al., 2008). Ainda, Zehra e Khan (2011) mencionam que existe correlação direta entre o consumo de proteína e a excreção de amônia. Essa correlação é mediada pelos processos de desaminação e/ou transaminação que liberam o grupo amino não reciclado por meio dos processos metabólicos, aumentando sua excreção, sendo esta considerada como perda energética pelos peixes (Das, 2002). O aumento na taxa de excreção de amônia com o maior consumo de proteína encontrado no presente estudo corrobora os estudos mencionados acima.

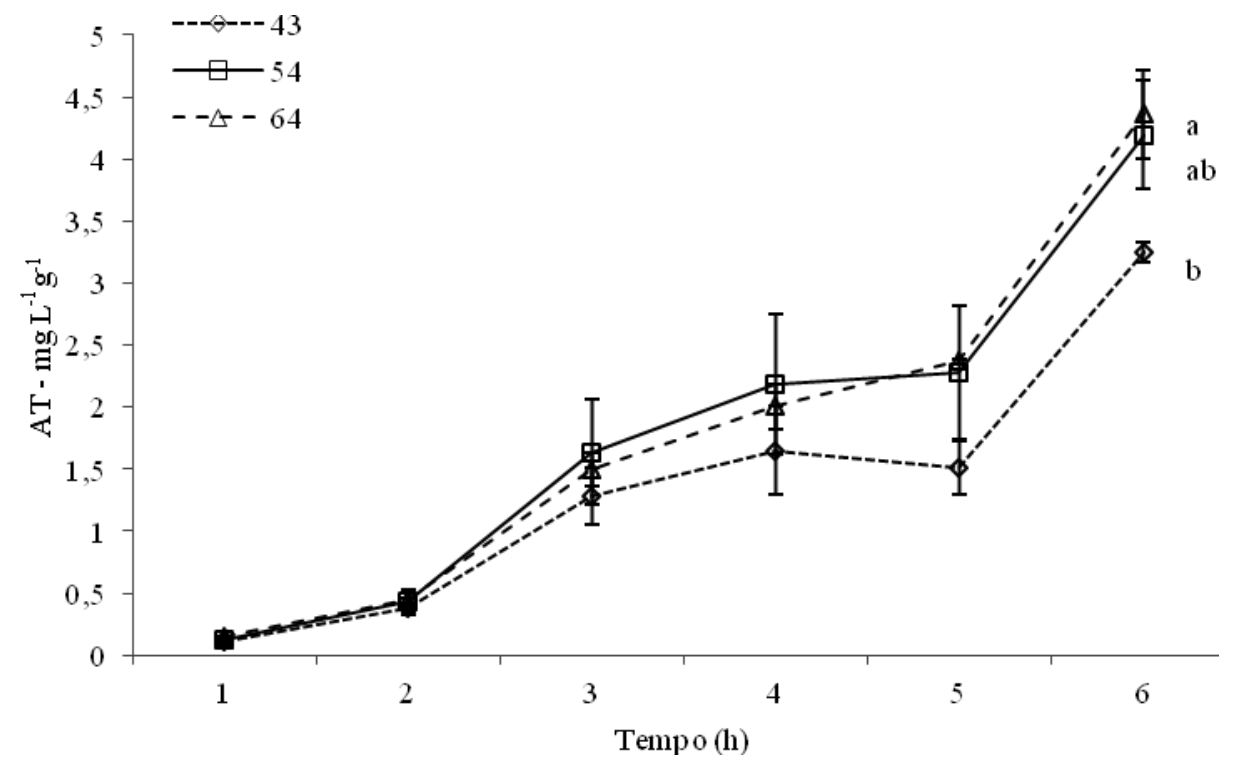

Figura 1. Taxa de excreção de amônia total - AT pós-prandial para juvenis de pampo Trachinotus marginatus alimentados com diferentes níveis de proteína na ração.

A menor taxa de excreção de amônia pósprandial do tratamento $\mathrm{PB} 43$ tem relação com a menor concentração da enzima transaminase glutâmico oxalacética (TGO) encontrada no fígado dos peixes desse tratamento (Tab. 4). A TGO é uma das principais enzimas de transaminação de aminoácidos (Jürss e Bastrop,
1995); ela transfere o radical nitrogenado do ácido aspártico para uma molécula de $\alpha$ cetoglutarato formando assim uma molécula de ácido oxalacético e outra de ácido glutâmico que, por sua vez, sofre desaminação para voltar à forma de $\alpha$-cetoglutarato liberando uma molécula de amônia gasosa que é então excretada. Nesse 
caso, o $\alpha$-cetoglutarato pode ser reutilizado em novas transaminações ou, caso se acumule no fígado, entrar como combustível no ciclo de Krebs, incrementando a obtenção de energia e sua deposição na forma de carboidratos e gordura (Das, 2002). A menor concentração da
TGO no fígado no tratamento PB43 pode ser resultante do efeito economizador de proteína proporcionado pelo maior teor de carboidratos dessa dieta, assim como encontrado para juvenis de Sparus aurata (Fernández et al., 2007).

Tabela 4. Metabólitos de juvenis de pampo Trachinotus marginatus alimentados com diferentes níveis de proteína na ração

\begin{tabular}{lccc}
\hline Tecido & \multicolumn{3}{c}{ Dieta } \\
\hline Variável & PB43 & PB54 & PB64 \\
\hline Fígado & $5,09 \pm 2,69 \mathrm{~b}$ & $13,32 \pm 3,6 \mathrm{a}$ & $6,31 \pm 2,30 \mathrm{~b}$ \\
TG & $0,44 \pm 0,15 \mathrm{~b}$ & $1,04 \pm 0,49 \mathrm{a}$ & $0,51 \pm 0,30 \mathrm{~b}$ \\
COL & $25,13 \pm 10,26$ & $27,99 \pm 4,47$ & $31,45 \pm 9,03$ \\
GG & $87,25 \pm 33,65$ & $76,66 \pm 15,61$ & $75,03 \pm 28,87$ \\
PT & $0,00048 \pm 0,0001 \mathrm{~b}$ & $0,00072 \pm 0,0002 \mathrm{ab}$ & $0,00088 \pm 0,0005^{\mathrm{a}}$ \\
TGO & $0,0099 \pm 0,005$ & $0,0112 \pm 0,005$ & $0,0129 \pm 0,006$ \\
TGP & & & \\
Músculo & $4,03 \pm 1,90 \mathrm{~b}$ & $7,56 \pm 2,75 \mathrm{a}$ & $7,74 \pm 3,01 \mathrm{a}$ \\
TG & $1,50 \pm 0,75$ & $0,67 \pm 0,45$ & $0,74 \pm 0,50$ \\
COL & $1,84 \pm 0,39$ & $2,50 \pm 1,15$ & $2,01 \pm 0,75$ \\
GG & $59,31 \pm 12,07$ & $60,57 \pm 15,71$ & $60,90 \pm 10,04$ \\
PT & $0,0148 \pm 0,003$ & $0,0144 \pm 0,004$ & $0,0133 \pm 0,003$ \\
TGO & $0,0162 \pm 0,006$ & $0,0157 \pm 0,006$ & $0,169 \pm 0,004$ \\
TGP & & &
\end{tabular}

Médias seguidas de letras diferentes, nas linhas, diferem entre si pelo teste de Duncan, a 5\% de probabilidade. TG: concentração de triglicérides totais ( $\mathrm{mg} \mathrm{g}$ de tecido úmido ${ }^{-1}$ ); COL: concentração de colesterol total (mg g de

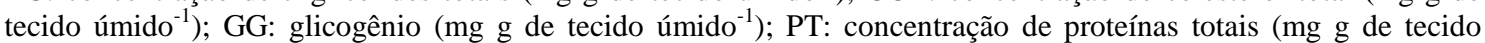
úmido $^{-1}$ ); TGO: transaminase glutâmica oxalacética (U.I mg de proteína de tecido ${ }^{-1}$ ) e TGP: transaminase glutâmica pirúvica (U.I mg de proteína tecido ${ }^{-1}$ ).

O conteúdo de glicogênio e proteína do fígado dos juvenis de pampo não apresentou diferença estatística entre os tratamentos (Tab. 4). Esse fato difere dos resultados encontrados por Yang et al. (2003) e Zamora-Sillero et al. (2013) que encontraram maior deposição de glicogênio hepático em peixes alimentados com maior concentração de carboidratos digestíveis. Por outro lado, esse órgão apresentou menor teor de triglicerídeos para o tratamento PB43 quando comparado ao tratamento PB54; esse mesmo padrão foi encontrado para o tecido muscular (Tab. 4). Esses dados sugerem que os triglicerídeos estejam sendo utilizados como material de deposição energética pelos peixes alimentados com $54 \%$ de proteína bruta. De fato, Jobling (2001) menciona que no fígado a principal fração lipídica depositada é o triglicerídeo.
O menor índice hepatossomático dos peixes do tratamento PB43, por sua vez, acorda com o menor teor de triglicerídeos no fígado e com a menor concentração da TGO hepática para os peixes desse tratamento, uma vez que menos proteína é utilizada como fonte energética na gliconeogênese, resultando em menor deposição de material de reserva no fígado.

\section{CONCLUSÕES}

O crescimento de juvenis de pampo não foi afetado pelo consumo de proteína. $\mathrm{O}$ excesso de proteína consumido aumenta a excreção de amônia pós-prandial após $6 \mathrm{~h}$ da alimentação. A proteína consumida é melhor aproveitada no nível de $43 \%$ de proteína bruta na dieta. 


\section{AGRADECIMENTOS}

À Coordenação de Aperfeiçoamento de Pessoal de Nível Superior (CAPES) pela concessão da bolsa de doutorado para Eduardo Martins da Silva, e ao $\mathrm{CNPq}$ pela Bolsa de Produtividade para Luís André Sampaio e José María Monserrat.

\section{REFERÊNCIAS}

AMADO, L.L.; GARCIA, M.L.; PEREIRA, T.C.B. et al. Chemoprotection of lipoic acid against microcystin-induced toxicosis in common carp (Cyprinus carpio, Cyprinidae). Comp. Biochem. Physiol., v.154, p.146-153, 2011.

AMERICAN Public Health Association - APHA. Standard methods for the examination of water and wastewater, 21st ed. APHA, Washington. 2005.

ASSOCIATION of offcial analytical chemists AOAC. Official methods of analysis. Arlington: AOAC International. 1995.

CARTER, C.G.; HOULIHAN, D.F. Protein synthesis. In: Nitrogen Excretion, Fish Physiology. WRIGHT, P.A., ANDERSON, A.J. (Eds.). v.20, San Diego: Academic Press, 2001. p.31-75.

CARVALHO, C.V.A.; BIANCHINI, A.; TESSER, M.B. et al. The effect of protein levels on growth, postprandial excretion and tryptic activity of juvenile mullet Mugil platanus (Günther). Aquac. Res., v.41, p.511-518, 2010.

CHO, S.H.; HEO, T.Y. Effect of dietary nutrient composition on compensatory growth of juvenile olive flounder Paralichthys olivaceus using different feeding regimes. Aquacult. Nutr., v.17, p.90-97, 2011.

COSTA, L.D.F.; MIRANDA-FILHO, K.C.; SEVERO, M.P. et al. Tolerance of juvenile pompano Trachinotus marginatus to acute ammonia and nitrite exposure at different salinity levels. Aquaculture, v.285, p.270-272, 2008.

CRAIG, S.R. Pompano Culture. In: Encyclopedia of aquaculture. Stickney, R.R. (Ed.). New York: Jonh Wiley \& Sons, USA, 2000. p.660-663.
DAS, D. Metabolism of proteins. In: Das, D. (ed) Biochemistry. New York: Academic Publishers, 2002. p.463-504.

FERNÁNDEZ, F.; MIQUEL, A.G.; CÓRDOBA, M. et al. Effects of diets with distinct protein-tocarbohydrate ratios on nutrient digestibility, growth performance, body composition and liver intermediary enzyme activities in gilthead sea bream (Sparus aurata, L.) fingerlings. J. Exp. Mar. Biol. Ecol., v.343, p.1-10, 2007.

FISCHER, L.G.; PEREIRA, L.E.D.; VIEIRA, J.P. Peixes estuarinos e costeiros. Rio Grande: Ecoscientia, 2004. p.127.

JOBLING, M. Nutrient partitioning and the influence of feed composition on body composition. In: Food Intake in Fish. Eds D. HOULIHAN, T. BOUJARD \& M. JOBLING. London: Blackwell Science Ltd, 2001. p.354375.

JORY, D.; IVERSEN, E.; LEWIS, R. Culture of the fishes of the genus Trachinotus Carangidae in the western Atlantic. J. World Maric. Soc., v.16, p.87-94, 1985.

JÜRSS, K.A.; BASTROP, R. Amino acid metabolism in fish. In: HOCHACHKA, P.W.; MOMMSEN, T.P. Metabolic Biochemistry. Biochemistry and molecular biology of fishes. Amsterdam: Elsevier Science, 1995. v.4, p.159190.

KUMAR, S.; SAHU, N.P.; PAL, A.K. et al. Modulation of key metabolic enzyme of Labeo rohita (Hamilton) juvenile: effect of dietary starch type, protein level and exogenous alphaamylase in the diet. Fish Physiol. Biochem., v.35, p.301-315, 2009.

LAIZ-CARRIÓN, R.; VIANA, I.R.; CEJAS, J.R. et al. Influence of food deprivation and high stocking density on energetic metabolism and stress response in red porgy, Pagrus pagrus L. Aquacult. Int., v.20, p.585-599, 2012.

LAZO, J.P.; DAVIS, D.A.; ARNOLD, C.R. The effects of dietary protein level on growth, feed efficiency and survival of juvenile Florida pompano (Trachinotus carolinus). Aquaculture, v.169, p.225-232, 1998.

LIMA, M.S.P.; VIEIRA, J.P. Variação espaçotemporal da ictiofauna da zona de arrebentação da Praia do Cassino, Rio Grande do Sul, Brasil. Zoologia, v.26, p.499-510, 2009. 
MARTÍNEZ-PALACIOS, C.A.; RÍOS-DURÁN, M.G.; AMBRIZ-CERVANTES, L. et al. Dietary protein requirement of juvenile Mexican Silverside (Menidia estor Jordan 1879), a stomachless zooplanktophagous fish. Aquacult. Nutr., v.13, p.304-310, 2007.

MELO, J.F.B.; LUNDSTEDT, L.M.; METÓN, I. et al. Effects of dietary levels of protein on nitrogenous metabolism of Rhamdia quelen (Teleostei, Pimelodidae). Comp. Biochem. Physiol., v.145, p.181-187, 2006.

NELSON, D.; COX, M. Lehninger, Principles of Biochemistry, 4. Ed.. New York: W.H. Freeman and Company, 2005. p.1167.

NERY, L.E.M.; SANTOS, E.A. Carbohydrate metabolism during osmoregulation in Chasmagnathus granulata, Dana, 1851 (Crustacea, Decapoda). Comp. Biochem. Physiol., v.106B, p.747-753, 1993.

PERES, H.; OLIVA-TELES, A. Effect of the dietary essential amino acid pattern on growth, feed utilization and nitrogen metabolism of European sea bass (Dicentrarchus labrax). Aquaculture, v.267, p.119-128, 2007.

REMA, P.; CONCEIÇÃO, L.E.C.; EVERS, F. et al. Optimal dietary protein levels in juvenile Senegalese sole (Solea senegalensis). Aquacult. Nutr., v.14, p.263-269, 2008.

SÁ, R.; POUSÃO-FERREIRA, P.; OLIVATELES, A. Dietary protein requirement of white sea bream (Diplodus sargus) juveniles. Aquacult. Nutr., v.14, p.309-317, 2008.

SAMPAIO, L.A.; TESSER, M.B.; BURKERT, D. Tolerância de juvenis do pampo Trachinotus marginatus (Teleostei, Carangidae) ao choque agudo de salinidade em laboratório. Cienc. Rural, v.33, p.757-761, 2003.
SIDDIQUI, T.Q.; KHAN, M.A. Effects of dietary protein levels on growth, feed utilization, protein retention efficiency and body composition of young Heteropneustes fossilis (Bloch). Fish Physiol. Biochem., v.35, p.479488, 2009.

SOLORZANO, L. Determination of ammonia in natural waters by the phenol hypocholorite method. Limnol. Oceanogr., v.14, p.700-801, 1969.

SOUZA, J.H.; FRACALOSSI, D.M.; GARCIA, A.S. et al. Desempenho zootécnico e econômico de juvenis de robalo peva alimentados com dietas contendo diferentes concentrações proteicas. Pesq. Agropec. Bras., v.46, p.190-195, 2011.

VIVAS, M.; RUBIO, V.C.; SANCHEZVAZQUEZ, F.J. et al. Dietary self-selection in sharpsnout seabream (Diplodus puntazzo) fed paired macronutrient feeds and challenged with protein dilution. Aquaculture, v.251, p.430-437, 2006.

YANG, S.D.; LIN, T.S.; LIOU, C.H. et al. Influence of dietary protein levels on growth performance, carcass composition and liver lipid classes of juvenile Spinibarbus hollandi (Oshima). Aquacult. Res., v.34, p.661-666, 2003.

ZAMORA-SILLERO, J.; RAMOS, L.R.V.; ROMANO, L.A. et al. Effect of dietary dextrin levels on the growth performance, blood chemistry, body composition, hepatic triglicerides and glycogen of Lebranche mullet juveniles (Mugil liza Valenciennes 1836, Mugilidae). J. App. Ichthyol., v.29, p.1342-1347. 2013.

ZEHRA, S.; KHAN, M.A. Dietary protein requirement for fingerling Channa punctatus (Bloch), based on growth, feed conversion, protein retention and biochemical composition. Aquacult. Int., v.20, p.383-395, 2011. 